\title{
A diagnostic method for distribution networks based on power supply safety standards
}

\author{
Junhui Huang ${ }^{1}$, Shaoyun Ge${ }^{2}$, Jun Han ${ }^{1}$, Hu Li ${ }^{1}$, Xiaomin Zhou², Hong Liu²* Bo Wang ${ }^{2}$ and Zhengfang Chen ${ }^{3}$
}

\begin{abstract}
In order to overcome the shortages of diagnostic method for distribution networks considering the reliability assessment, this paper proposed a method based on power supply safety standards. It profoundly analyzed the security standard of supply for urban power networks, and established quantitative indicators of load groups based on different fault conditions. Then a method suitable for diagnostic evaluation of urban distribution networks in China was given. In the method, "N-1" calibration analysis of the distribution network was conducted. Then the results are compared with quantitative indicators of load groups on different conditions deriving the diagnostic conclusions and the standard revision is discussed. The feasibility and accuracy of the method is finally verified in the case study.
\end{abstract}

Keywords: Distribution network, Diagnostic process, N-1 calibration analysis, Power supply security

\section{Introduction}

With the rapid development of social economy and continuous improvement of people's living standards, the terminal users of urban power networks require more secure and reliable supply [1]. Therefore, the major problem and technical difficulty the urban power networks are facing in China are how to invest moderately to meet the security and reliability of supply which can be accepted by the users [2]. To solve the technical difficulty, the primary task is finding an appropriate method to diagnose power grid structure and investigate the realistic condition of grid operation. At present, reliability assessment is usually used.

However, as the main method of security diagnosis, reliability assessment has many shortages. It mainly focuses on three aspects, which are the frequency, duration and range of interruptions. Reliability indexes can reflect supply condition at every point of the system [3]. At present, the frequency of interruptions mainly relies on statistics of people, which cannot realistically reflect the situation of the grid due to great personal factors.

\footnotetext{
* Correspondence: liuhong@tju.edu.cn

${ }^{2}$ Key Laboratory of Smart Grid of Ministry of Education, Tianjin University,

Tianjin 300072, China

Full list of author information is available at the end of the article
}

Although the duration and range of interruptions can be obtained by the network, quantitative indicators are used to determine whether they comply with safety standards. Therefore, the criterion of supply security needs to be studied by utilizing the data sources and operational experience and basing on the practical situation of urban power networks, in order to provide the theoretical fundamentals and solutions of improving security of urban power networks in China.

To obtain the method of security diagnosis, this paper firstly analyses the basic concept on the safety standards of power supply and obtains the quantitative indicators by confirming the relevant regulations and evaluation index of "supply security". Then, a set of diagnostic evaluation method, which is suitable for Chinese urban distribution networks, is constructed based on these indexes and "N-1" calibration results. The security of the grid in different conditions are analyzed and the solutions of improving the security of networks are proposed. In this way, the diagnosis for the distribution networks changes from qualitative indicators to quantitative ones, which is a guide to the development of the distribution networks and improvement of operation and maintenance in different regions. 


\section{Methods}

\section{Security criterion analysis of supply}

Learning from the advanced technologies and ideas of othercountries and considering the background in China, the National Energy Administration issued the power supply security standard, DT/T 256-2012, for urban networks. The reliability level of supply not only depends on the quality of components and the level of operation and maintenance but also the damage of the load after components' outage [4]. The security criterion of supply and safety standards should be set to meet the requirements of security diagnosis [5].

\section{Power supply security standards for urban areas}

The regulations are comparatively specific in the power supply security standards for urban areas in China, which chooses common load groups in distribution networks. The security level suitable for distribution networks is indicated in Table 1.

\section{Supply security criterion analysis for urban areas}

According to the network structure in China, the capacity of the common equipment is shown in Table 2 [6].

In this table, the loading rate of transformer is $50 \% \sim 70 \%$. The capacity of the line is calculated by $S=\sqrt{3} U I$, where $U$ is the voltage of the line, and $I$ is the carrying capacity of the line. Considering lines can not be operated with full loading, $40 \% \sim 50 \%$ of the capacity was picked as the transmission capacity of the line.

The load groups are divided into 6 levels A to Fin terms of their sizes, based on the power supply security standards for urban networks in China $[7,8]$. The higher level the load is, the shorter the restoring time is after the circuit outage, and the higher the extent of recovery is.

This paper focuses on the security diagnosis of distribution networks where the levels $\mathrm{A}$ to $\mathrm{C}$ of the load groups are selected for analysis.

A. The load group ranges between 0 and $2 \mathrm{MW}$. The typical capacity of a $10 / 0.4 \mathrm{kV}$ transformer is from 0.015 to $1 \mathrm{MVA}$. Two neighboring section switches divide several (usually less than 5) 10/0.4 kV transformers into a unit. The load of every unit is from 0 to $2 \mathrm{MV}$ and does not need to be supplied by the other circuits.

B. The load group varies from 2 to $12 \mathrm{MW}$. The transmission capacity of a $10 \mathrm{kV}$ line is $3-4 \mathrm{MV}$. The common capacity of a $35 / 10 \mathrm{kV}$ transformer is 31.5MVA, 20MVA, 16MVA and 5MVA. The typical capacity of a $35 / 10 \mathrm{kV}$ substation can be $5 * 2 \mathrm{MVA}$, 16*2MVA, whose load is between 5 and $10 \mathrm{MW}$.

C. The load group ranges from 12 to $180 \mathrm{MW}$. The transmission capacity of a $35 \mathrm{kV}$ line is $12-15 \mathrm{MV}$. The common capacity of a $110 / 10 \mathrm{kV}$ transformer is 63MVA, 50MVA, 40MVA, 31.5MVA and 20MVA. The typical capacity components of a $35 / 10 \mathrm{kV}$ substation are $31.5^{*} 2 \mathrm{MVA}, 40 * 2 \mathrm{MVA}, 50 * 2 \mathrm{MVA}$, 63*2MVA and 63*4MVA, whose load is between 30 and $170 \mathrm{MW}$.

The quantification of the restoration capacity is different at the different levels of the load groups [9]. The specific analysis can be stated as follows:

(1) Load groups-2 MW. $2 \mathrm{MW}$ is the maximum load of a segment on a medium voltage $10 \mathrm{kV}$ line. Load group-2 MW represents a load of MV line without the outage segment.

(2) Load groups-12 MW. $12 \mathrm{MW}$ is a load of a $35 \mathrm{kV}$ line. Load group-12 MW represents a total load of a $110 / 10 \mathrm{kV}$ substation minus the load of a $35 \mathrm{kV}$ line.

(3) Load groups-60 MW. $60 \mathrm{MW}$ is a load of a $110 \mathrm{kV}$ line. Load groups-60 MW represents a total load of a $220 / 110 \mathrm{kV}$ substation minus the load of a $110 \mathrm{kV}$ line.

(4) $2 / 3$ of load groups. By analyzing the situation of China, the typical capacity, in summary, is $2 / 3$ of the annual peak load (the typical load is the level under which the load in $80 \%$ of evaluation time should be). So the load group of $\mathrm{C}$ does not lose the load in the case of the "N-1" planned outages while losing a part of the load in the case of the "N-1" failure outage. Network reconfiguration by the remote operation can regain 2/3 of load groups. After $3 \mathrm{~h}$, all load groups recover.

Table 1 Security standards of supply for urban China (common load groups in distribution networks)

\begin{tabular}{|c|c|c|c|c|}
\hline Supply level & Scope of load groups (MW) & "N-1" outage & "N-1-1" outage & commen \\
\hline A & $\leq 2$ & After maintenance: restore load groups & No requirement & \\
\hline B & $2 \sim 12$ & $\begin{array}{l}\text { (1) In } 3 \mathrm{~h} \text { : load restored = load groups- } 2 \mathrm{MW} \\
\text { (2) After maintenance: restore load groups }\end{array}$ & No requirement & \\
\hline C & $12 \sim 180$ & $\begin{array}{l}\text { (1) In } 15 \text { min: load restored } \geq \min \text { (load groups-12 MW, 2/3 load groups). } \\
\text { (2) In } 3 \text { h: restore load groups }\end{array}$ & No requirement & $*[a]$ \\
\hline
\end{tabular}

*[a]: User group is generally supplied by two (or more than two) normally-closed circuits or one circuit but can be switch to other circuits by artificial or automatic switch. The load group is the maximum load of the use group

The table above shows that the "N-1" outage is the main point to be considered in distribution networks 
Table 2 Capacity of common equipment in China

\begin{tabular}{llll}
\hline Equipment & $\begin{array}{l}\text { Common capacity of transformer/Limiting } \\
\text { capacity of line (MVA/MW) }\end{array}$ & $\begin{array}{l}\text { Load of transformer/transmission } \\
\text { capacity of line (MW/MW) }\end{array}$ & Load level \\
\hline $10 / 0.4$ kV Transformer & $1,0.8,0.5,0.4,0.315,0.2,0.05$ & 0.5 & A \\
10 kV Line & 8 & $3 \sim 4$ & B \\
$35 / 10$ kV Transformer & $20,16,5$ & $5 \sim 10$ & B \\
$110 / 10$ kV Transformer & $63,50,40,31.5,20$ & $30 \sim 170$ & $C$ \\
35 kV Line & 30 & $12 \sim 15$ & $C$ \\
110 kV Line & 100 & $40 \sim 50$ & $C$ \\
\hline
\end{tabular}

\section{Security diagnostic process}

\section{Security diagnostic process of supply}

After analyzing the power supply security standards for urban areas in China and establishing the basis of quantitative indicators, the security diagnostic process can be established, which is shown in Fig. 1.

In this figure, based on the quantitative outcomes of the power supply security standards for urban areas in China, a "N-1" verification module was firstly used for grid analysis, and then deal with the results together with the comparison module to derive conclusions and solutions. The whole assessment process is specifically introduced as follows.

\section{"N-1" Verification module}

The inputted network structure is mainly verified with the "N-1" contingency by this module. The components that cannot pass the "N-1" verification are marked, and the load transfer schemes of components are given and the sizes of the loads are recorded if passing the verification [10]. Based on the "N-1" calibration, topology analysis, connection mode analysis, power flow calculation and transfer scheme analysis are used to verify the grids, completely and comprehensively $[11,12]$.

The basic data processing module consists of three parts: topology analysis, connection mode analysis and power flow calculation, which is shown in Fig. 2.

The raw data of the system is combining through, and the result is converted to be used by power flow calculation mentioned in "N-1" verification. The connection between main transformers and lines, and the information of switches' state are obtained from the topology analysis to prepare data for a set of switching operation choices in the calculation of "N-1" verification. The output power of the main transformers and the power flow through components can be obtained by the power flow calculation to prepare data for the maximum transfer load of the main transformers and

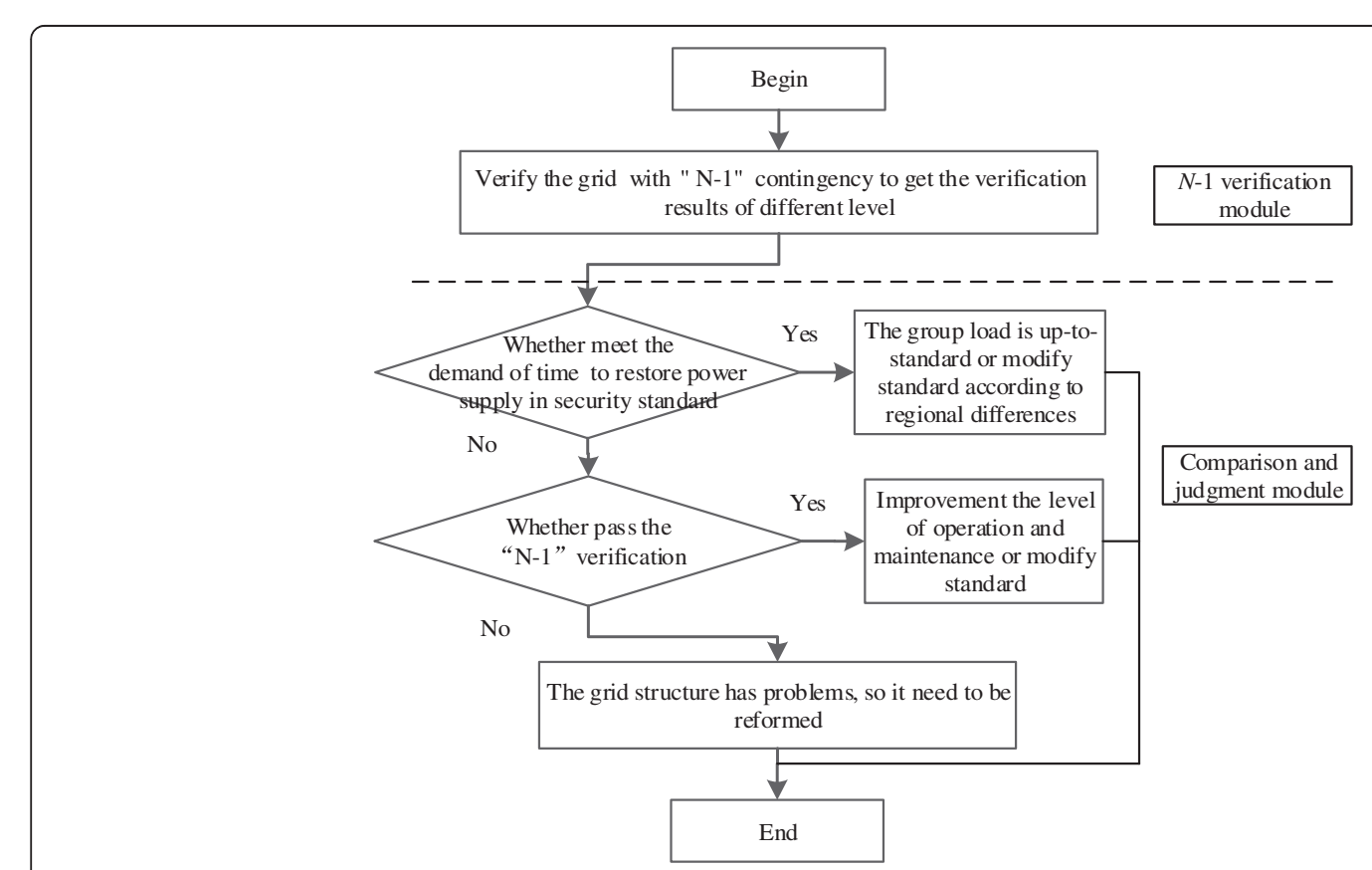

Fig. 1 Sketch of diagnosis process for distribution network 


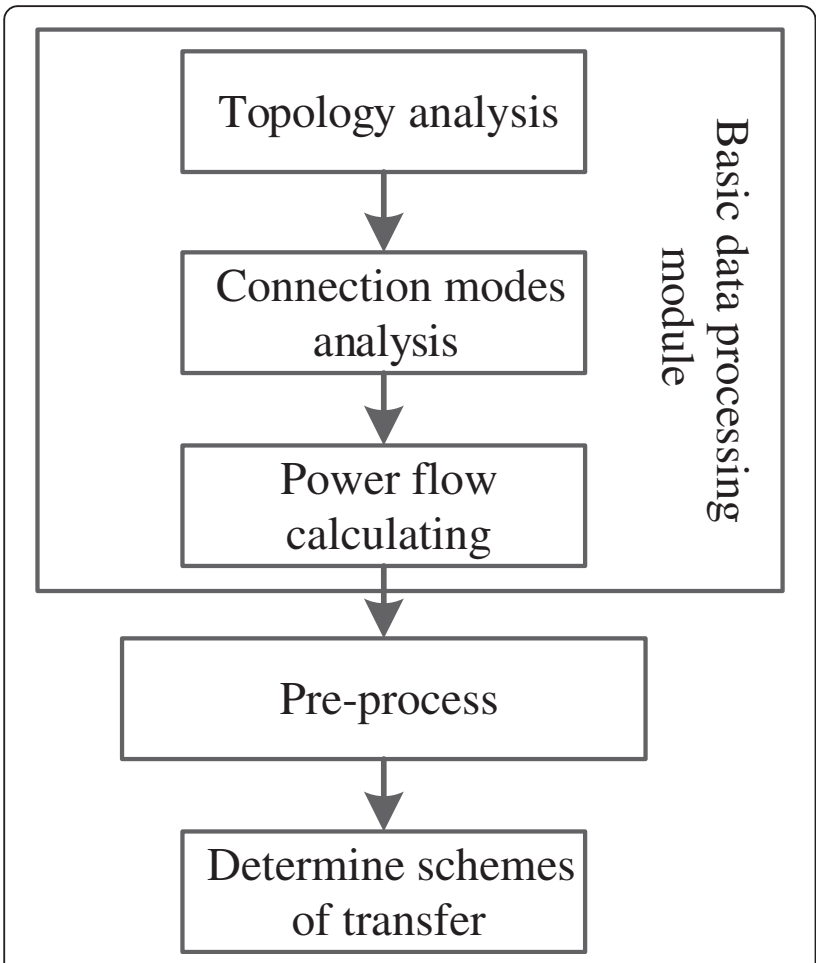

Fig. 2 Components of " $\mathrm{N}-1$ " verification module

the lines. Furthermore, connection mode analysis and power flow calculation are combined to prepare for "N-1" verification.

The pre-processing has two functions: eliminating the data which cannot obviously pass the verification and put them into the result table; and selecting the data which can obviously pass the verification and put them into the result table. The rest data is put into the table of components that need to be verified.

The data that cannot obviously pass the verification includes the single radial line obtained through the topology and connection mode analysis, which has no way to be transferred. If there's a failure at outlet section of the substation bus, it will lead a wide outage in the area. So the single radial line can be directly determined.

The data that can obviously pass the verification is the situation where the main transformer with the maximum capacity in the substation has a failure and another main transformer can supply all the loads in the substation. So this situation can be directly determined.

The pre-processing effectively reduces the number of components meant to be verified, which can simplify the process and improve the speed of verification.

Determining schemes of transfer are the core parts of the "N-1" verification module. Its function is to verify the components and record the size of the transferred load.

\section{Comparison and judgment module}

After analyzing the grid with the "N-1" verification module, the Verification Result Table can be derived, which records whether the components pass the verification, the way to transfer and the size of the transferred load. The comparison is conducted from 3 aspects: failure of the line, failure of the main transformer and the outage of the substation [13].

Furthermore, according to the size of transferred loads and the length of transferring time, comparing with the power supply security standards for urban areas in China, the analyzing results are obtained and the solutions of improving the security of networks can be proposed.

By comparing the Verification Result Table with power supply security standards for urban areas in China, following a differential and hierarchical way to check one by one, the comparison result has a high reliability. Based on this, the network structure is further analyzed.

The load groups of different levels all meet the demand in power supply security standards for urban areas in China. This kind of loads meets the details of the standard from two aspects of transferring time and the size of transferred loads. Because different regions possess differing development levels, if the practice time is usually shorter than the standard, the standard can be modified to drive the development the network structure and the level of operation and maintenance.

There are load groups of some levels do not meet the power supply security standards for urban areas in China. This kind of loads can not meet the details of standard from two aspects that load can't be transferred or transferred load don't meet load capacity required [14]. The Result Table of "N-1" verification is checked to get the information whether the components pass the verification.

(1) If the component can pass the verification, the reason of being substandard is that the time of manual reconstructing is too long when the load is transferred, so the level of operation and maintenance should be improved $[15,16]$. At the same time, the practical situation of the region should be considered. If they can't generally meet the standard, the standard needs to be modified to fit the region.

(2) If only a part of the component cannot pass the verification, the reason of being substandard is structure of power network, so the network should be reformed [17]. How to reform the network is a difficult issue which is not discussed in this paper. 


\section{Results and discussion}

Combined with the diagnostic method for the distribution networks based on power supply safety standards, a case study is conducted to verify the correctness of the proposed method.

\section{Diagnosis of region-A}

According to the diagnostic method and process above, the region-A is analysed as a case to verify the feasibility of this method. And the practical case of the structural parameters and the analysis results are displayed as follows.

There are three substations in the region- $\mathrm{A}$, whose diagram is shown in Fig. 3. Station A1 is a $110 \mathrm{kV}$ substation located in the northwest, and the power supplies a part of the industrial applications at the north of Road and a few residential applications. Currently, there are 26 lines in the coverage of this regional power supply. Station A2 is a $35 \mathrm{kV}$ substation in the southwest, which mainly supplies for the western residential applications. Correspondingly, there are 16 lines. And the $35 \mathrm{KV}$ station A3 located in the mid-east like A2, mainly supplies for the western residential applications, but it has 14 lines. The A2 and A3 cannot be interconnected because of the natural barrier.

The time standards of the operation and maintenance level are: $10 \mathrm{~h}$ for breakdown maintenance; $5 \mathrm{~h}$ for manual reconstruction; $20 \mathrm{~min}$ for remote control reconstruction and $60 \mathrm{~s}$ for automatic switching.

\section{"N-1" Calibration results of region- $\mathrm{A}$}

According to the above method, region-A is verified with "N-1" calibration, which includes the main transformers and lines.

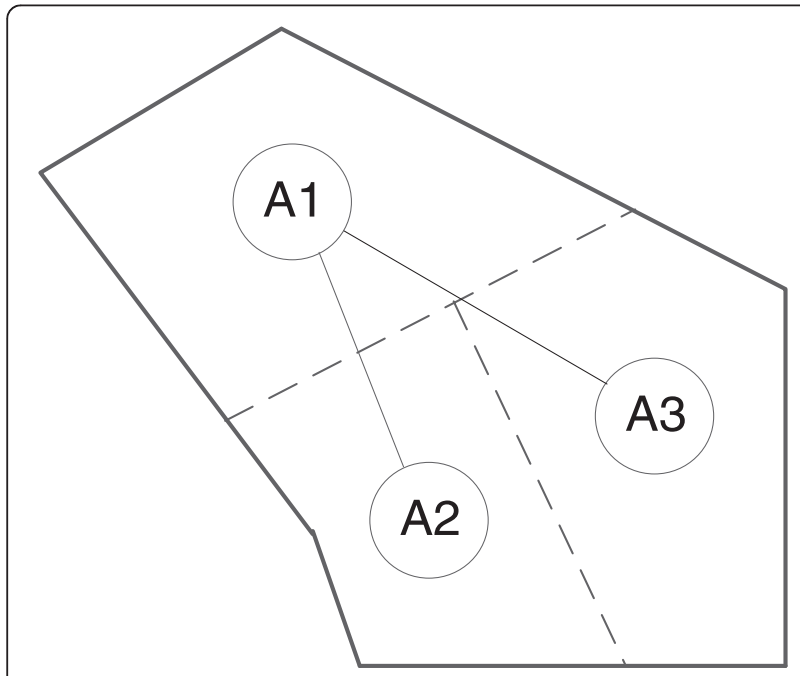

Fig. 3 Diagram of substation distribution in region-A
According to the diagnostic process, the "N-1" calibration results of the lines and main transformers are obtained, as indicated in Tables 3 and 4.

\section{Comparative analysis results of region-A}

When there is a fault at the line, it is divided into two parts, which are the faulty section and non-faulty section. For the faulty section, the power is restored after maintenance tasks, so it is necessary to ensure that whether maintenance time could meet the safety standard requirements. For the non-faulty section, the transferring time is checked because its load can be transferred by the link line. The following analysis assumes that the automation level of region-A is relatively low, and the transferring is based on the manual switching operation.

According to the analysis results above, the detailed descriptions are stated as follows.

(1) Line 5, 6, 7, 8 in Station A1, Line 39, 40, 41, 42 in Station A2, and Line 51, 52, 53, 54, 55, 56 in Station A3. These single-radiation lines cannot pass the "N-1" calibration. When there are faults, the loads cannot be transferred, so the power supply for the non-faulty section comes after maintenance. The load class of some lines (Line 5, 6, 8, 39, 40, 41, 42, 51, 52, 53, 55 and 56) can be expressed as A, and the maintenance time of them is $10 \mathrm{~h}$, which cannot meet the safety standard requirements. Besides, carrying the large load, Line 7 in Station A1 and Line 54 in Station A3 can be expressed as B and cannot transfer all of load required when faults happen, so they must be upgraded to transfer load and their transferring time should meet the safety standard requirements.

(2) Line 10 in Station A1 and Line 45 in Station A3. These lines with single tie cannot satisfy the "N-1" calibration owing to the lack of transferring capacity. For the non-faulty section, either $5 \mathrm{~h}$ for transferring or $10 \mathrm{~h}$ for maintaining to restore the power supply cannot meet the safety standard requirements.

(3) Remain lines. They have ties and could pass "N-1" calibration. But similarly, $5 \mathrm{~h}$ for transferring to restore the power supply would not meet the safety standard requirements.

According to the analysis above, the operation and maintenance level of this region cannot satisfy the safety standard requirements; especially, there are two lines (Line 7, 54) which need to be improved, so the operation and maintenance level of this region should be upgraded.

When there are faults in the main transformers, internal transferring of station should be considered firstly. It can be completed automatically, and the time is about $60 \mathrm{~s}$. If the loading rates of main transformers are high, 
Table 3 "N-1" calibration results of $10 \mathrm{kV}$ lines in region-A

\begin{tabular}{|c|c|c|c|c|c|c|c|c|c|c|c|}
\hline Substation & $\begin{array}{l}\text { Line } \\
\text { name }\end{array}$ & $\begin{array}{l}\text { Connection } \\
\text { type }\end{array}$ & $\begin{array}{l}\text { Line } \\
\text { load } \\
\text { (kW) }\end{array}$ & $\begin{array}{l}\text { Translational } \\
\text { load (kW) }\end{array}$ & $\begin{array}{l}\text { Whether } \\
\text { pass }\end{array}$ & Substation & $\begin{array}{l}\text { Line } \\
\text { name }\end{array}$ & $\begin{array}{l}\text { Connection } \\
\text { type }\end{array}$ & $\begin{array}{l}\text { Line } \\
\text { load } \\
\text { (kW) }\end{array}$ & $\begin{array}{l}\text { Translational } \\
\text { load }(\mathrm{kW})\end{array}$ & $\begin{array}{l}\text { Whether } \\
\text { pass }\end{array}$ \\
\hline $\bar{A} 1$ & Line 1 & Single-tie & 1524 & 2476 & Yes & $A 2$ & Line 29 & Multi-tie & 1120 & 2880 & Yes \\
\hline $\mathrm{A} 1$ & Line 2 & Multi- tie & 1653 & 1347 & Yes & $A 2$ & Line 30 & Multi-tie & 1333 & 2267 & Yes \\
\hline $\mathrm{A} 1$ & Line 3 & Multi-tie & 2387 & 1613 & Yes & $A 2$ & Line 31 & Multi-tie & 1519 & 2481 & Yes \\
\hline $\mathrm{A} 1$ & Line 4 & Single-tie & 1559 & 2441 & Yes & $\mathrm{A} 2$ & Line 32 & Multi-tie & 1021 & 1979 & Yes \\
\hline $\mathrm{A} 1$ & Line 5 & Single-radiation & 1346 & - & No & $A 2$ & Line 33 & Single-tie & 1105 & 2895 & Yes \\
\hline $\mathrm{A} 1$ & Line 6 & Single-radiation & 1847 & - & No & $A 2$ & Line 34 & Single-tie & 1231 & 2469 & Yes \\
\hline $\mathrm{A} 1$ & Line 7 & Single-radiation & 2044 & - & No & $A 2$ & Line 35 & Single-tie & 1152 & 2648 & Yes \\
\hline $\mathrm{A} 1$ & Line 8 & Single-radiation & 1523 & - & No & $A 2$ & Line 36 & Single-tie & 1226 & 2774 & Yes \\
\hline $\mathrm{A} 1$ & Line 9 & Multi-tie & 2102 & 1860 & Yes & $A 2$ & Line 37 & Multi-tie & 1237 & 2763 & Yes \\
\hline $\mathrm{A} 1$ & Line 10 & Single-tie & 1879 & 2121 & No & $A 2$ & Line 38 & Single-tie & 1032 & 2868 & Yes \\
\hline $\mathrm{A} 1$ & Line 11 & Multi-tie & 1865 & 2135 & Yes & $A 2$ & Line 39 & Single-radiation & 1255 & - & No \\
\hline $\mathrm{A} 1$ & Line 12 & Multi-tie & 1623 & 2377 & Yes & $\mathrm{A} 2$ & Line 40 & Single-radiation & 1065 & - & No \\
\hline $\mathrm{A} 1$ & Line 13 & Multi-tie & 1116 & 2884 & Yes & $A 2$ & Line 41 & Single-radiation & 1126 & - & No \\
\hline $\mathrm{A} 1$ & Line 14 & Multi-tie & 1356 & 2644 & Yes & $A 2$ & Line 42 & Single-radiation & 1176 & - & No \\
\hline $\mathrm{A} 1$ & Line 15 & Multi-tie & 1645 & 2355 & Yes & A3 & Line 43 & Multi-tie & 1744 & 2256 & Yes \\
\hline $\mathrm{A} 1$ & Line 16 & Multi-tie & 2496 & 1504 & Yes & A3 & Line 44 & Multi-tie & 1206 & 2794 & Yes \\
\hline $\mathrm{A} 1$ & Line 17 & Multi-tie & 1212 & 2788 & Yes & A3 & Line 45 & Multi-tie & 2343 & 1857 & No \\
\hline $\mathrm{A} 1$ & Line 18 & Single-tie & 1742 & 2258 & Yes & A3 & Line 46 & Multi-tie & 1542 & 2258 & Yes \\
\hline $\mathrm{A} 1$ & Line 19 & Single-tie & 1435 & 2565 & Yes & A3 & Line 47 & Single-tie & 1615 & 2385 & Yes \\
\hline $\mathrm{A} 1$ & Line 20 & Single-tie & 1318 & 2682 & Yes & A3 & Line 48 & Multi-tie & 1375 & 2625 & Yes \\
\hline $\mathrm{A} 1$ & Line 21 & Multi-tie & 1764 & 2236 & Yes & A3 & Line 49 & Single-tie & 1464 & 2536 & Yes \\
\hline $\mathrm{A} 1$ & Line 22 & Single-tie & 2317 & 1683 & Yes & A3 & Line 50 & Single-tie & 1717 & 2283 & Yes \\
\hline $\mathrm{A} 1$ & Line 23 & Single-tie & 1435 & 2565 & Yes & A3 & Line 51 & Single-radiation & 1032 & - & No \\
\hline $\mathrm{A} 1$ & Line 24 & Single-tie & 1767 & 1206 & Yes & A3 & Line 52 & Single-radiation & 1390 & - & No \\
\hline $\mathrm{A} 1$ & Line 25 & Single-tie & 1232 & 2768 & Yes & A3 & Line 53 & Single-radiation & 1258 & - & No \\
\hline $\mathrm{A} 1$ & Line 26 & Single-tie & 2315 & 1685 & Yes & A3 & Line 54 & Single-radiation & 1015 & - & No \\
\hline$A 2$ & Line 27 & Single-tie & 1235 & 2565 & Yes & A3 & Line 55 & Single-radiation & 1265 & - & No \\
\hline$A 2$ & Line 28 & Single-tie & 1167 & 1206 & Yes & $\mathrm{A} 3$ & Line 56 & Single-radiation & 1034 & - & No \\
\hline
\end{tabular}

internal transferring of station would not supply the power to all lines, so the excess lines would be cut. And then connections between stations should be taking into account. If there is a sufficient connection capacity between stations, the load will be transferred by other stations. Accordingly, whether the transferring time reaches the safety standard requirements can be confirmed. The rest part, which cannot be transferred, gets power supply after maintenance. The results after failure of transformers are shown as Table 5 .

According to the power supply safety standards, it requests $8 \mathrm{~h}$ for breakdown maintenance, $3 \mathrm{~h}$ form anual reconstruction to restore the power supply and $60 \mathrm{~s}$ for automatic switching.

Table 4 " $\mathrm{N}-1$ " calibration results of main transformers in region-A

\begin{tabular}{lllllllll}
\hline Region & Substation & Load (MW) & $\begin{array}{l}\text { Main transformer } \\
\text { capacity (MVA) }\end{array}$ & $\begin{array}{l}\text { Total capacity of } \\
\text { 10KV Part (MVA) }\end{array}$ & $\begin{array}{l}\text { Translational load } \\
\text { of link line (MVA) }\end{array}$ & $\begin{array}{l}\text { Translational Load } \\
\text { of main trans (MVA) }\end{array}$ & Whether pass & $\begin{array}{l}\text { Loss load } \\
\text { A }\end{array}$ \\
\cline { 2 - 3 } & A1 & 41.3 & $2 \times 40$ & 80 & 5.7 & 40 & No & 1.3 \\
& A2 & 23 & $2 \times 20$ & 40 & 5.7 & 20 & No & 3 \\
& A3 & 21 & $2 \times 20$ & 40 & 0 & 20 & No & 1 \\
\hline
\end{tabular}


Table 5 Failure analyses results of transformers in region-A

\begin{tabular}{llllllllll}
\hline $\begin{array}{l}\text { Region } \\
\text { Substation } \\
\text { name }\end{array}$ & $\begin{array}{l}\text { Load } \\
\text { (MW) }\end{array}$ & $\begin{array}{l}\text { Main transformer } \\
\text { Capacity (MVA) }\end{array}$ & $\begin{array}{l}\text { Total } \\
\text { capacity } \\
\text { (MVA) }\end{array}$ & $\begin{array}{l}\text { Translational load of } \\
\text { main trans (MW) }\end{array}$ & $\begin{array}{l}\text { Recovery } \\
\text { time }\end{array}$ & $\begin{array}{l}\text { Translational load } \\
\text { of lines (MW) }\end{array}$ & $\begin{array}{l}\text { Recovery } \\
\text { time }\end{array}$ & $\begin{array}{l}\text { Loss } \\
\text { load } \\
\text { (MW) }\end{array}$ & $\begin{array}{l}\text { Recovery } \\
\text { time }\end{array}$ \\
\hline A & A1 & 41.3 & $2 \times 40$ & 80 & 40 & $60 \mathrm{~s}$ & 1.3 & 5 & 0 \\
& A2 & 19 & $2 \times 20$ & 40 & 19 & $60 \mathrm{~s}$ & 3 & 5 & 0 \\
& A3 & 20 & $2 \times 20$ & 40 & 20 & $60 \mathrm{~s}$ & 0 & - & - \\
\end{tabular}

According to the analysis results above, the detailed descriptions are shown as follows.

(1) Substation A1: Assuming that each main transformer could carry $130 \%$ of the load when faults happen in another transformer, then the total load of the faulty transformer would be transferred through automatic internal transferring of station in $60 \mathrm{~s}$, which reaches the safety standard requirements. Assuming that each main transformer could carry $100 \%$ of the load, and the automatic switching could make a part of loads transferred, the remaining part would be transferred through the connection between stations, therefore there will be 1.3 MW load transferred in $5 \mathrm{~h}$, which cannot reach the safety standard in view of the overlong time.

(2) Substation A2: Assuming that each main transformer could carry $130 \%$ of the load when faults happen in another transformer, then the total load of the faulty transformer would be transferred through automatic internal transferring of station in $60 \mathrm{~s}$, which reaches the safety standard requirements. Assuming that each one could carry $100 \%$ of the load, and the automatic switching could make a part of loads transferred, the remain part would be transferred through the connection between stations, therefore there will be a $3 \mathrm{MW}$ load transferred in $5 \mathrm{~h}$, which cannot reach the safety standard requirements in view of the overlong time.

(3) Substation A3: Assuming that each main transformer could carry $130 \%$ of the load when faults happen in another transformer, then the total load of the faulty transformer would be transferred through automatic transferring in station in $60 \mathrm{~s}$, which reaches the safety standard requirements. Assuming that each one could carry $100 \%$ of the load, and the automatic switching could make a part of loads transferred, different from the above, the remaining part would not be transferred due to the lack of connection between stations; therefore the $1 \mathrm{MW}$ load would get power supply only after the $10 \mathrm{~h}$ maintenance, which cannot reach the safety standard requirements.

\section{Summary of analysis results}

A2 and A3 cannot be interconnected because of the natural barrier, so the connection condition of the whole region is poor. Carrying a large load, defined as Class B, Line 7 in Station A1 and Line 54 in Station A3 cannot transfer loads to reach the standard when there is a failure. Obviously, it is necessary to upgrade these lines. Besides, a lot of single-radiation lines urge the region to improve the structure of the network. The low operation and maintenance level also makes region A cannot reach the power supply safety standard. However, it is more appropriate to revise this standard to avoid the negative impact of the strict rules on regional development. Therefore, in order to adapt to the actual situation and promote the level of operation and maintenance, $9 \mathrm{~h}$ for breakdown maintenance and $4 \mathrm{~h}$ form anual reconstruction are set up.

\section{Conclusions}

As the power supply safety standards need to be improved, the diagnostic method using the reliability index cannot offer the quantitative analysis of the power grid structure. The diagnostic method for distribution networks based on power supply safety standards has the following characteristics:

(1) The power supply safety standard has profound theoretical basis, a practical background and strict logic. It is a complete quantitative criterion, which is simple, clear and easy to use. According to the actual situation of Chinese urban power grids, it can fully reflect the structure performance level of Chinese power grid currently, based on practical experience in many years and the results of the survey.

(2) The diagnostic method has a distinct and strong structure. The standards considering the actual situation are not only distinguished from different levels of loads, but also from the grid structure level.

(3) In view of the different levels of structure, it is significant to make a quantitative index distinguishing the difference, so this standard has a great guiding significance for the diagnosis of the distribution networks. 
To summarize, this standard can be used to give appropriate solutions of improving the security of networks and revise the safety standard on the basis of the regional characteristics.

\section{Authors' contributions}

$J H$ and SG proposed the diagnostic process of the distribution network. JH, $H L, X Z$, and $H L$ carried out the theoretical studies and drafted the manuscript. BW and ZC performed the case study. All authors read and approved the final manuscript.

\section{About the Authors'}

Junhui Huang (1965-), male, received bachelor degrees from Nanjing Engineering College (Southeast University) in 1987. He was deputy chief engineer of the Jiangsu Electric Power designs institute from 1987 to 2006, deputy director of the Jiangsu Electric Power Company Power Grid Planning Research Center from 2006 to 2011, and is director of the Jiangsu Electric Power Company Economic Research Institute Power Grid Planning Assessment Center now. His major is the planning and management of power network, Email: xshhih@126.com. ShaoyunGe (1964-), male, received master degrees from School of electric automation engineering in Tianjin University and acquired his Ph.D. from Hong Kong University. He is now a Professor of Tianjin University. His major is urban power system programming and automation of distribution system. Moreover he has published more than 20 papers in IEEE. Email: syge@tju.edu.cn. Jun Han (1985-), male, received bachelor degrees from Hunan University in 2008 and acquired master and Ph.D. degrees from School of electric automation engineering in Tianjin University in 2013 and is an engineer in the Jiangsu Electric Power Company Economic Research Institute. His major is the planning of distribution network and the application of the theory, Email: hjchallenge@126.com.

Hu Li (1979-), male, received bachelor and master degrees from Xi'an Jiaotong University in 2000 and 2003, respectively. He worked at the Jiangsu Electric Power designs institute from 2003 to 2006, the Jiangsu Electric Power Company Power Grid Planning Research Center from 2006 to 2011, and work at the Jiangsu Electric Power Company Economic Research Institute now. His major is the planning and designing of distribution network. Email: tigerli110@163.com.

Xiaomin Zhou (1992-), female, received bachelor degrees at School of electric automation engineering in Tianjin University and now is studying for Master at the same University, Her major is the planning of distribution network, Email: zhouxiaomin@tju.edu.cn

Hong Liu (1979-), male, received master and Ph.D. degrees from School of electric automation engineering in Tianjin University in 2005 and 2009, respectively. Major in the planning and evaluation of distribution network and Smart Grid, Email: liuhong@tju.edu.cn.

Bo Wang (1993-), female, now is studying for Master at School of electric automation engineering in Tianjin University, Her major is the planning of distribution network, Email: Wangbo@163.com.

Zhengfang Chen (1963-), male, Bachelor anda Engineerin the Suzhou Electric Power Company, Major in the planning of distribution network, Email:wlys2000@163.com.

\section{Competing interests}

The authors declare that they have no competing interests.

\section{Author details}

'State Grid Jiangsu Economic Research Institute, Nanjing, Jiangsu province, 210008, China. ${ }^{2}$ Key Laboratory of Smart Grid of Ministry of Education, Tianjin University, Tianjin 300072, China. ${ }^{3}$ State grid Suzhou Power Supply

Company, Suzhou, Jiangsu province, 215000, China.

Received: 13 May 2016 Accepted: 16 May 2016

Published online: 28 June 2016

\section{References}

1. Ming D, Jing Z, \& Shenghu L. (2004). Research on the Model for Distribution Network Reliability Evaluation Based on Sequential Monte-Carol Simulation []]. Power System Technology, 28(3), 38-42 (in Chinese).

2. Qunhui G, An L \& Ji W. (2003). A Practicable Algorithm to Forecast and Evaluate Reliability of Power Supply []. Power System Technology, 27(12), 76-79. (in Chinese).
3. Xiu-ren L, Zhen R, \& Wenying H. (2005). Unascertained Mathematical Approach to Management of Uncertainty in Reliability Evaluation of Distribution Systems []]. Automation of Electric Power Systems, 29(17), 28-33 (in Chinese).

4. Yu H, \& Jidong L. (2001). Cost-benefit Analysis and Evaluation of Power Network Planning []]. Power System Technology, 25(7), 32-35 (in Chinese).

5. Qian Z, Yang X, \& Wang X. (2008). Discussion on Security of Power Supply Engineering Recommendation ER P2/6 of UK [J]. Power System Technology, 32(18), 96-102 (in Chinese).

6. Zhichao Z, Yan Z, Wang W, \& Mao J. (2004). Quantitative Evaluation of Substation Supply Reliability [J]. Automation of Electric Power Systems, 28(9), 66-69 (in Chinese).

7. Wenyuan L. (2002). Incorporating Aging Failures in Power System Reliability Evaluation[J]. IEEE Trans. On Power Systems, 17, 3.

8. Mingtian F, \& Zuping Z. (2008). Researchon the Development Strategy of distributed networks in China[M]. Beijing: China Electric Power Press (in Chinese).

9. Wenyuan Li \& Billinton R. (2003). Common Cause Outage Models in Power System Reliability Evaluation[J]. IEEE Trans. On Power Systems, 18, 2.

10. Pengxiang B, Jian L, Chunxin L, \& Wenyuan Z. (2002). A Refined Genetic Algorithm for Power Distribution Network Reconfiguration [J]. Automation of Electric Power Systems, 26(2), 57-61 (in Chinese).

11. Liu C-C, \& Lee SJ. (1988). An expert system operational aid for restoration and loss reduction of distribution systems [J]. IEEE Transactions on Power Systems, 3(2), 619-626.

12. Nagata T, Sasaki H, \& Yokoyama R. (1995). Power system restoration by joint usage of expert system and mathematical programming approach [J]. IEEE Transactions on Power Systems, 10(3), 1473-1478.

13. Guo Y. (2003). Power System Reliability Analysis [M] (p. 1). Beijing: Tsinghua University Press. in Chinese.

14. Lee Willis H. (1997). Power Distribution Planning Reference Book [M]. NewYork: MarcelDekke.INC.

15. Fan Mingtian. (2007). Comparison the Standards of Power Supply Security for Urban Power Network at Home and Abroad [J]. Distribution \& Utilization, 24(5), 5-8. in Chinese.

16. Zhu H, Cheng H, \& Zhang Yan HZ. (1999). A Review of Electric Power Network Flexible Planning [J]. Automation of Electric Power Systems, 23(17), 38-4. 1 (in Chinese).

17. JianNing WZ, Wei N, \& Yang X. (2007). Constructing Nanjin Urban Power Network with Advanced World Idea of Power Network Planning []]. Distribution \& Utilization, 24(5), 1-4 (in Chinese).

\section{Submit your manuscript to a SpringerOpen ${ }^{\mathcal{O}}$ journal and benefit from:}

- Convenient online submission

Rigorous peer review

- Immediate publication on acceptance

- Open access: articles freely available online

- High visibility within the field

- Retaining the copyright to your article

Submit your next manuscript at $\boldsymbol{s p r i n g e r o p e n . c o m ~}$ 